\title{
PENGARUH CITRA MEREK, INOVASI PRODUK, DAN KEPUASAN KONSUMEN TERHADAP KEPUTUSAN PEMBELIAN KFC GAJAHMADA SIDOARJO
}

\author{
Devi Elisya Faddilah¹, I Made Bagus Dwiarta² \\ Universitas PGRI Adi Buana Surabaya ${ }^{1,2}$ \\ Email : elisyachaca@gmail.comํ․ bagusdwiarta@gmail.com²
}

\begin{abstract}
ABSTRAK
Mencari hasil dari pengaruhnya citra merek, inovasi produk, kepuasan konsumen terhadap keputusan pembelian di KFC Cabang GajahMada Sidoarjo. Penelitian diambil dari seluruh konsumen yang melakukan pembelian di KFC GajahMada Sidoarjo. Metode yang di pakai Non Probability Sampling, teknik Sampling Insidental, 114 responden, di harapkan pihak manajemen KFC GajahMada Sidoarjo agar fokus dalam meningkatkan daya beli konsumen supaya tetap membeli lagi di perusahaan tersebut. Hasil uji $F$ berkata sig $0.000<0.05$ maka X1, X2, X3 secara bersama dipengaruhi oleh keputusan pembelian.
\end{abstract}

Kata Kunci: citra merek, inovasi produk, kepuasan konsumen, keputusan pembelian.

\begin{abstract}
Looking for results from the influence of brand image, product innovation, customer satisfaction with purchasing decisions at KFC Gajah Mada Sidoarjo. The research was taken from all consumers who made purchases at KFC Gajah Mada Sidoarjo. The method used is Non-Probability Sampling, Incidental Sampling technique, 114 respondents are expected by the KFC Gajah Mada Sidoarjo to focus on increasing the purchasing power of consumers so that they continue to buy again in the company. F-test results said sig $0.000>0.05$ then $X 1, X 2, X 3$ together are influenced by purchasing decisions.
\end{abstract}

Keywords: brand image, product innovation, customer satisfaction, purchasing decisions. 


\section{PENDAHULUAN}

Di jaman yang semakin canggih saat ini di bidang industri makanan dan minuman mengalami perkembangan yang pesat dam banyak saingan. Sudah banyak yang membuka gerai makanan dan minuman seperti depot, cafe, atau restoran fast food mulai meluas di Indonesia.

Konsumen pun semakin selektif menentukan pilihan makanan yang diinginkannya. Untuk itu restoran sangat memperhatikan apa saja yang dibutuhkan konsumen baik dalam rasa, juga penyajian agar terciptanya kepuasan untuk konsumen yang beli.

Dengan kepuasan konsumen meliputi hasil kerja produk agar seimbang seperti yang di harapkan pembeli, Kotler dan Amstrong (2009). Citra merek pun menjadi peran yang penting sebab bisa dibedakan antara perusahaan dan kompetitor.

KFC ditetapkan dalam Top Brand Award 2019 Fase 2 survei. KFC juga mempunyai Top Brand Index (TBI) 2019 KFC 26.2\%.

Penelitian dilakukan di KFC GajahMada di Sidoarjo. Berlokasi sangat strategis mudah dijangkau di tengah kota, dengan daerah bisnis sejenisnya. Maka dari itu tempat ini sangat sering di datangi banyak orang.

Jumlah pelanggan selama bulan Januari-Desember 2018 sebanyak 64.828 (Sumber: Internal KFC Gajah Mada Sidoarjo). Jumlah pelanggan KFC Cabang Gajah Mada Sidoarjo mengalami kenaikan setiap bulannya karena KFC Cabang GajahMada Sidoarjo melihat strategi yang dipakai untuk menawarkan produknya agar penjualan terus meningkat khususnya mengalami peningkatan pada Bulan Desember 2018 sebesar 7.055 pelanggan. Di buktikan KFC Cabang GajahMada Sidoarjo selalu menaikkan penjualan agar tidak kalah saing dengan perusahaan fast food lainnya dan kelangsungan hidup perusahaan dapat di pertahankan.

Munculnya fenomena terbaru di awal tahun 2019 yang dilakukan KFC khususnya di KFC Gajahmada Sidoarjo menerapkan "Budaya Bereskan Sampah Bekas Makanan Sendiri" \#BudayaBeberes wujud kepedulian KFC Indonesia terhadap lingkungan.

Peneliti memilih KFC Gajahmada Sidoarjo sebagai objek "Pengaruh Citra Merek .X1, Inovasi Produk .X2, Kepuasan Konsumen .X3 terhadap Keputusan Pembelian .Y di KFC Gajahmada Sidoarjo". Munculah teori tersebut yang dituangkan dalam kerangka konseptual:

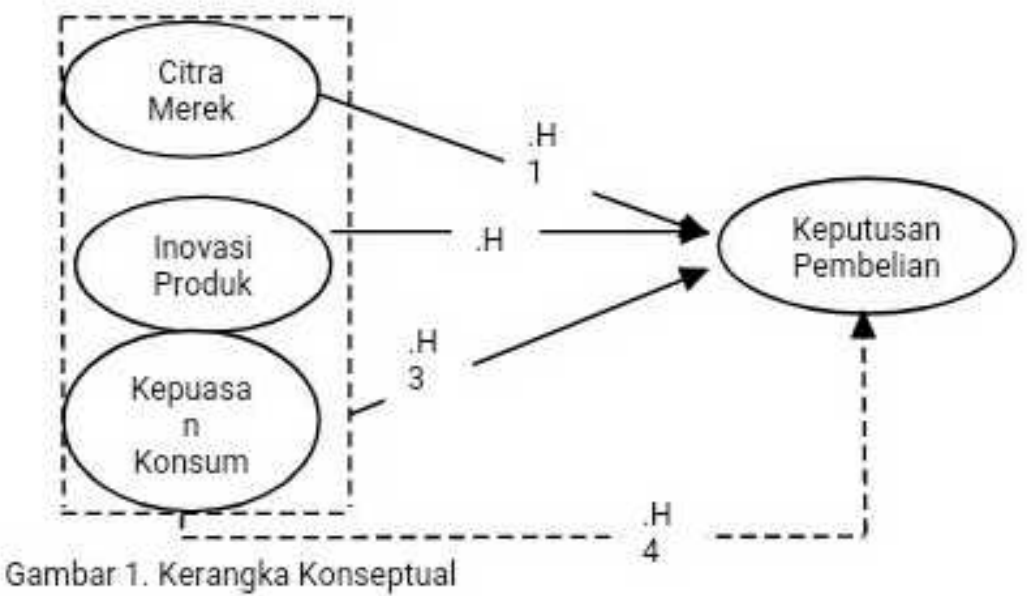


Keterangan kerangka konseptual, variabel bebas X1, X2, X3, terhadap variabel terikat yaitu Y. Sesuai hasil diatas, maka diajukan hipotesis:

$\mathrm{H} 1$ : Keputusan pembelian konsumen dipengaruhi citra merek KFC GajahMada Sidoarjo

$\mathrm{H} 2$ : Keputusan pembelian konsumen dipengaruhi inovasi produk KFC GajahMada Sidoarjo

H3 : Keputusan pembelian konsumen dipengaruhi kepuasan konsumen KFC GajahMada Sidoarjo H4 : Keputusan pembelian konsumen bersimultan dipengaruhi citra merek, inovasi produk, kepuasan konsumen KFC GajahMada Sidoarjo.

\section{METODE}

Seluruh konsumen yang melakukan pembelian di KFC Gajahmada Sidoarjo sebanyak 114, Sampling Non Probabilitas. Jenis datanya di dapat model angka serta analisisnya statistik.

\section{ALAT PENGUMPULAN DATA}

Sumber data yang di pakai peneliti data primer didapat oleh penulis dengan cara menyebar kuesioner kepada konsumen yang memutuskan pembelian di KFC GajahMada Sidoarjo dan data sekunder seperti internet, buku-buku, dan catatan. Mengumpulkan data melalui sebar kuesioner menggunakan skala likert SPSS versi 25. Penelitian di KFC Gajahmada Sidoarjo, berlokasi Jl. GajahMada No.82, Daleman. Pekauman Sidoarjo. 


\section{HASIL}

Dari uji yang dilakukan terhadap 114 responden KFC Gajahmada Sidoarjo menyebarkan angket kuesioner:

Tabel 1. Distribution Frequency Variabel Citra Merek, Inovasi Produk dan Kepuasan Konsumen

\begin{tabular}{|c|c|c|c|c|c|c|}
\hline \multirow{2}{*}{$\begin{array}{l}\text { Urai } \\
\text { an }\end{array}$} & \multicolumn{4}{|c|}{ Frekuensi (\%) } & \multicolumn{2}{|c|}{$\begin{array}{c}\text { Total } \\
(\%)\end{array}$} \\
\hline & $\begin{array}{l}S \\
S\end{array}$ & $S$ & $\begin{array}{l}R \\
G\end{array}$ & $\begin{array}{l}T \\
\text { S }\end{array}$ & $\begin{array}{l}S \\
T \\
S\end{array}$ & \\
\hline $\mathrm{X} 1$ & 28,9 & 46,5 & $\begin{array}{l}1 \\
9 \\
3\end{array}$ & 3 & 1,8 & 100 \\
\hline $\mathrm{X} 2$ & 37,7 & 37,7 & $\begin{array}{l}2 \\
2, \\
8\end{array}$ & 0 & 0,9 & 100 \\
\hline X3 & 28,1 & 29,8 & $\begin{array}{l}2 \\
8, \\
9\end{array}$ & 9 & 3,5 & 100 \\
\hline Y & 25,4 & 39,5 & $\begin{array}{l}2 \\
8, \\
1\end{array}$ & 5 & 1,8 & 100 \\
\hline
\end{tabular}

Sumber : Lampiran Output SPSS Distribution Frequency 2020

Tabel 1 menunjukan karyawan setuju dengan adanya variabel citra merek, inovasi produk, dan kepuasan konsumen di KFC Gajahmada Sidoarjo.

Tabel 2. Result Validity Test

\begin{tabular}{|c|c|c|c|c|}
\hline Indikator & $\begin{array}{l}\text { Ite } \\
\text { m }\end{array}$ & $\begin{array}{c}\mathrm{r}- \\
\text { hitung }\end{array}$ & $\begin{array}{c}r- \\
\text { tab } \\
\text { el }\end{array}$ & $\begin{array}{c}\text { Keterang } \\
\text { an } \\
\text { "Valid" }\end{array}$ \\
\hline \multicolumn{5}{|l|}{$\mathrm{X} 1$} \\
\hline 1.1 & 1 & 0,665 & .3 & \\
\hline 1.2 & 2 & 0,698 & .3 & \\
\hline 2.1 & 1 & 0,614 & .3 & \\
\hline 2.2 & 2 & 0,711 & .3 & \\
\hline 3.1 & 1 & 0,579 & .3 & \\
\hline 3.2 & 2 & 0,658 & .3 & \\
\hline 4.1 & 1 & 0,706 & .3 & \\
\hline 4.2 & 2 & 0,697 & .3 & \\
\hline 5.1 & 1 & 0,667 & .3 & \\
\hline 5.3 & 2 & 0,733 & .3 & \\
\hline 6.1 & 1 & 0,782 & .3 & \\
\hline 6.2 & 2 & 0,770 & .3 & \\
\hline 7.1 & 1 & 0,709 & .3 & \\
\hline 7.2 & 2 & 0,630 & .3 & \\
\hline 8.1 & 1 & 0,472 & .3 & \\
\hline 8.2 & 2 & 0,764 & .3 & \\
\hline 9.1 & 1 & 0,718 & .3 & \\
\hline 9.2 & 2 & 0,790 & .3 & \\
\hline \multicolumn{5}{|l|}{$\mathrm{X} 2$} \\
\hline 1.1 & 1 & 0,799 & .3 & \\
\hline 1.2 & 2 & 0,688 & .3 & \\
\hline 2.1 & 1 & 0,783 & .3 & \\
\hline 2.2 & 2 & 0,837 & .3 & \\
\hline 3.1 & 1 & 0,804 & .3 & \\
\hline 3.2 & 2 & 0,760 & .3 & \\
\hline \multicolumn{5}{|l|}{$\mathrm{X3}$} \\
\hline 1.1 & 1 & 0,738 & .3 & \\
\hline 1.2 & 2 & 0,853 & .3 & \\
\hline 2.1 & 1 & 0,743 & .3 & \\
\hline 2.2 & 2 & 0,712 & .3 & \\
\hline 3.1 & 1 & 0,804 & .3 & \\
\hline
\end{tabular}

\begin{tabular}{lllll}
\hline 3.2 & 2 & 0,792 & .3 \\
\hline 4.1 & 1 & 0,815 & .3 \\
\hline$Y$ & 2 & 0,743 & .3 \\
\hline 4.2 & & & \\
\hline 1.1 & 1 & 0,765 & .3 \\
\hline 1.2 & 2 & 0,766 & .3 \\
\hline 2.1 & 1 & 0,820 & .3 \\
\hline 2.2 & 2 & 0,793 & .3 \\
\hline 3.1 & 1 & 0,817 & .3 \\
\hline 3.2 & 2 & 0,887 & .3
\end{tabular}

Sumber : Lampiran Output SPSS 
Dari tes tersebut $X 1, X 2, X 3$ dan $Y$, semuanya valid nilai sig $5 \%<$ dengan nilai $r$ hitung $>r$ tabel.

Tabel 3. Result Reability Test

\begin{tabular}{cccc}
\hline Variabel & $\begin{array}{c}\text { Croanbach } \\
\text { Alpha }\end{array}$ & $\begin{array}{c}\text { Reliabilitas } \\
\text { Minimum }\end{array}$ & $\begin{array}{c}\text { Keterangan } \\
\text { "Reliabel" }\end{array}$ \\
\hline${ }^{*}$ X1 & .949 & .6 & \\
\hline${ }^{*} \mathrm{X} 2$ & .914 & .6 & \\
\hline${ }^{*} \mathrm{X} 3$ & .914 & .6 & \\
\hline${ }^{*} \mathrm{Y}$ & .916 & .6 & \\
\hline
\end{tabular}

Sumber : Lampiran Output SPSS Reability Test 2020

Nilai Croanbach Alpha ke semua variabel > 0.6. Untuk itu dinyatakan reliabel.

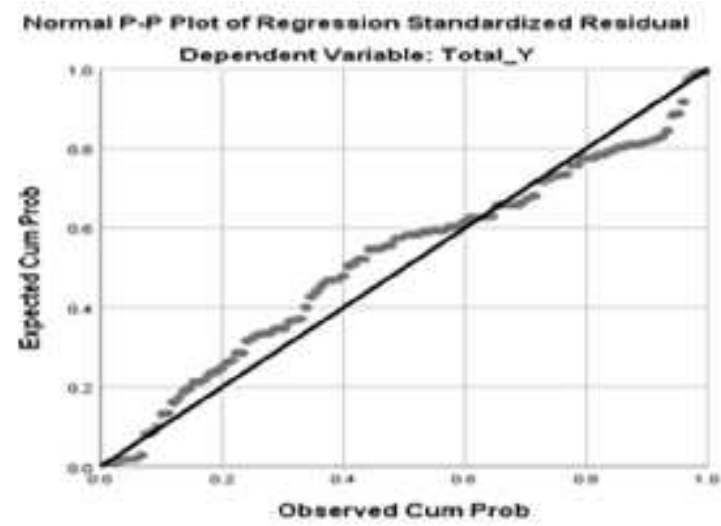

Gambar 2. Uji Normalitas P-Plot

Normal p-plot terlihat bulat-bulat yang mengikuti dan mendekati garis diagonalnya. Berarti disumpulkan model regresi menandakan asumsi normalitas, sehingga layak untuk dilanjutkan analisis data.

Tabel 4. Multicollinearity test result

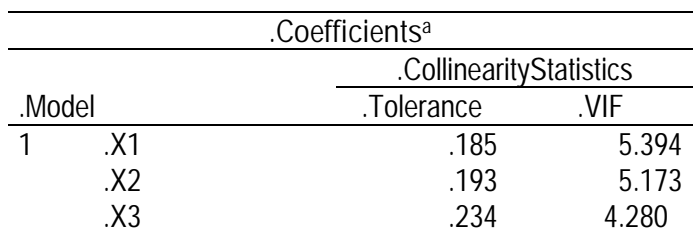

Dependent Variable: Keputusan Pembelian $Y$

Source: Appendix SPSS Output classic assumptions

Melihat tabel 4, VIF X1 sebesar 5,394 $(5,394<10)$, X2 sebesar 5,173 $(5,173<10)$. X3 sebesar $4,280(4,280<10)$. Dinyatakan untuk regresi linier berganda penelitian yang diteliti bebas dari multikolinieritas 


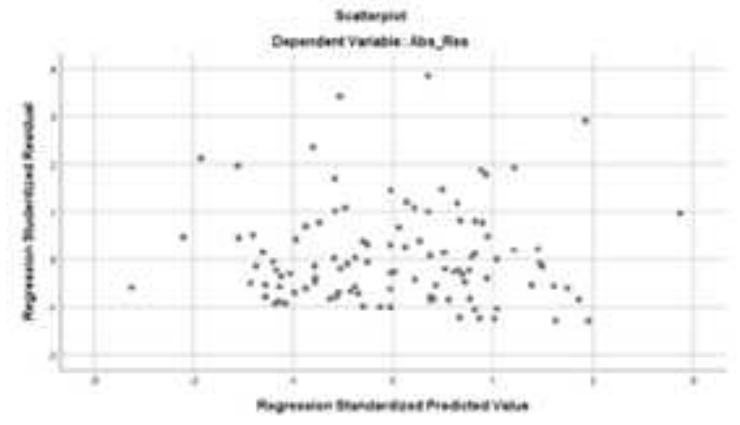

Gambar 3. Heteroscedasticity test result Scatterplot

Uji tersebut bisa dilihat tidak berbentuk serta bulat yang ada dibawah dan diatas angka 0 , model regresi tidak terkena heteroscedasticity, sehingga layak untuk dilanjutkan analisis data.

Table 5. Autocorrelation test result

\begin{tabular}{cc}
\hline & \multicolumn{2}{c}{ Model Summary } \\
\hline Model & Durbin-Watson \\
\hline 1 & $1.861^{\mathrm{a}}$ \\
\hline
\end{tabular}

a. Prediktor: X1, X2, X3

b. Variabel tak bebas: $Y$

Source: Appendix SPSS Output classic assumptions

Nilai DW sebesar 1,861 lebih besar dari nilai (dl dan du), maka dinyatakan regresi linear bebas dari autokolerasi.

Table 6. Test result of multiple linear

\begin{tabular}{lrrrl}
\hline Variabel & $\begin{array}{r}\text { Unstand } \\
\text { ardized } \\
\text { Coefficie } \\
\text { nts (B) }\end{array}$ & $\begin{array}{c}\text { t- } \\
\text { hitung }\end{array}$ & Sig. & Keterangan \\
\hline Constant & .042 & .025 & .980 & \\
\hline X1 & .083 & 1.542 & .126 & \\
\hline X2 & .068 & .482 & .631 & \\
\hline X3 & .483 & 5.007 & .000 & Signifikan \\
\hline
\end{tabular}

Sumber: Lampiran Output SPSS Regresi Linier Berganda

Table. 7. t-test result 


\begin{tabular}{ccc}
\hline $\begin{array}{c}\text { *Standardized } \\
\text { Coefficients }\end{array}$ & $\mathrm{t}$ & Sig \\
\hline (Constant) & .042 & .980 \\
\hline $\mathrm{X} 1$ & .083 & .126 \\
\hline $\mathrm{X} 2$ & .048 & .631 \\
\hline $\mathrm{X} 3$ & .043 & .000 \\
\hline
\end{tabular}

Source: attachment output spss

a. Variabel Dependen : $Y$

Adapun hasil uji-t diperoleh hasil sebagai berikut:

Pengujian Hipotesis 1

Dalam hipotesis "X1 berpengaruh pada Y di KFC Gajah Mada Sidoarjo". Tabel nilai t-hitung variabel kreativitas 0.083 sig 0.126 diperoleh hasil $0.126>0.05$. Berarti hypothesis ditolak artinya $\mathrm{X} 1$ berpengaruh pada Y di KFC Gajah Mada terbukti tidak benar.

Pengujian Hipotesis 2

Hipotesis "X2 berpengaruh pada Y di KFC Gajah Mada". Tabel t-count variable kreativitas 0.048 sig 0.631 diperoleh hasil $0.631>0.05$.

Hipotesis 3

Hipotesis ini tentang "X3 berpengaruh pada $Y$ di KFC Gajah Mada". Tabel nilai t-hitung variabel kreativitas $0.043 \mathrm{sig} 0.000$ diperoleh hasil $0.000<0.05$. Untuk itu hipotesis diterima artinya $\mathrm{X} 3$ berpengaruh pada Y di KFC Gajah Mada terbukti benar.

Table 8. test result $F$

\begin{tabular}{ccc}
\hline Model & F & Signifikan \\
\hline Regresi & 70,203 & $.000^{\mathrm{b}}$ \\
\hline Residual & & \\
\hline Total & & \\
\hline
\end{tabular}

a. Variabel Dependen : $Y$

b. Preditor: X1, X2, X3

Source: attachment output spss 2020

Dalam hasil Anova result F-hitung 70,203 sig .000. Diperoleh sig $0.000<0.05$ maka X1, X2, X3 Secara bersama dipengaruhi oleh keputusan pembelian.

\section{PEMBUKTIAN HIPOTESIS DAN PEMBAHASAN}

Hipotesis 1 memakai t result yang diperoleh variabel X1 0,083 sig 0.126. Disimpulkan Hipotesis ditolak. Keputusan pembelian tidak dipengaruhi citra merek di KFC GajahMada Sidoarjo. 
Untuk hipotesis 2 membuat Uji t yang diperoleh t-hitung variable X2 0.048 sig 0.631 . Disimpulkan Hipotesis ditolak. Keputusan pembelian tidak dipengaruhi inovasiproduk di KFC GajahMada.

Terakhir hipotesis 3 memakai Uji-t. t-hitung variabel X3 0.043 sig 0.000. Disimpulkan Hipotesis diterima. Keputusan pembelian dipengaruhi kepuasan konsumen di KFC GajahMada Sidoarjo.

\section{SIMPULAN}

Dari keempat hasil X1, X2, dan X3 yang telah di teliti oleh peneliti tidak semuanya berpengaruh terhadap $Y$ dijelaskan tergantung dari kebijakan yang di buat perusahaan yang tiap tahunnya di revisi dan telah di tentukan sesuai SOP (Standart Operational Procedure) yang berlaku.

Dalam hasil uji F semua variable X1, X2, X3 berpengaruh terhadap Y di KFC Gajah Mada Sidoarjo yang berarti hipotesis diterima dan berpengaruh positif secara bersama.

\section{IMPLIKASI}

KFC Gajah Mada Sidoarjo sebaiknya tetap bertahan pada konsistensi citra merek yang telah ada di KFC itu sendiri, memunculkan ide inovasi yang kreatif guna menjaga produk agar tidak kalah saing dengan kompetitor di bidang yang sama sehingga konsumen merasa puas akan apa yang KFC berikan.

Perusahaan juga memperluas sistem pemasaran dapat menarik konsumen juga mengerti karakteristik setiap konsumen sehingga konsumen tertarik membeli di KFC Gajah Mada Sidoarjo karena factor pribadi konsumen berpengaruh pada keputusan pembelian konsumen.

\section{KETERBATASAN PENELITIAN}

Variabel yang dilibatkan sedikit. Maka pada penelitian berikutnya perlu untuk menambahkan berbagai variabel, sehingga cakupan variabel lebih luas.

\section{DAFTAR PUSTAKA}

Al Rasyid, Harun dan Agus Tri Indah 2018. Pengaruh Inovasi Produk dan Harga Terhadap Keputusan Pembelian Sepeda Motor Yamaha di Kota Tangerang Selatan. Jakarta: Jurnal p-ISSN: 14118637 e ISSN: 2550-1178

Antonius Ong, Ian dan Drs. Sugiono Sugiharto, M.M, 2013. Analisa Pengaruh Strategi Diferensiasi, Citra Merek, Kualitas Produk Dan Harga Terhadap Keputusan Pembelian Pelanggan Di Cincau Station, Surabaya. Jurnal Manajemen Pemasaran Vol. 1, No. 2, (2013) 1-11.

Amstrong, Kotler 2008. Prinsip-Prinsip Pemasaran Edisi 12 Jilid 1 Penerbit Erlangga.

Assauri, Prof. Dr. Sofjan MBA 2018. Manajemen Bisnis Pemasaran. Depok: Rajawali Pers.

Fatlahah, Aniek 2013. Pengaruh Kualitas Produk Dan Citra Merek Terhadap Keputusan Pembelian Es Krim Wall's Magnum. Surabaya: Jurnal IImu Manajemen, Volume 1 Nomor 2 Maret 2013.

Ferdinand, Augusty 2014. Metode Penelitian Manajemen Pedoman Penelitian untuk Penulisan Skripsi, Tesis dan Desertasi IImu Manajemen. Edisi Kedua. Semarang: Badan Penerbit Universitas Diponegoro.

Hidayat, Rahmat 2015. Pengaruh Kepuasan Konsumen Terhadap Keputusan Pembelian Lampu Philips (Studi Kasus Pada Mahasiswa Telkom University), Bandung. Jurnal ISSN: 2355-0295.

Philip and Gary Armstrong, Kotler 2012. Prinsip-prinsip Pemasaran. Edisi 13. Jilid 1. Jakarta : Erlangga. 
Philip, Kotler dan Keller, Kevin Lane 2012. Manajemen Pemasaran, Edisi Ke 14, Jakarta, Erlangga. Jasa Terminix di Kota Manado. Junal EMBA Vol. 1 No. 4 Desember 2013 Hal 105-114.

Permadi, Prima Conny dan Srikandi Kumadji, Andriani Kusumawati. 2014. Pengaruh Citra Merek Terhadap Word Of Mouth Dan Keputusan Pembelian (Survei Pada Konsumen Dapoer Mie Galau Jalan Selorejo 83 Malang), Fakultas Ilmu Administrasi, Universitas Brawijaya, Malang.

Sugiyono, 2019, Metode Penelitian Kuantitatif Kualitatif dan R\&D, Alfabeta, Bandung.

Tjiptono Ph. D, Fandy 2015. Strategi Pemasaran, Yogyakarta.

Wiratna, Sujarweni V 2019. SPSS untuk Penelitian, Pustaka Baru Press, Yogyakarta. 